Running head: I/ECMH in NICU

\title{
Infant/Early Childhood Mental Health and Collaborative Partnerships: Beyond the NICU
}

\author{
Angela M. Tomlin, PhD \\ Riley Child Development Center LEND and Indiana University School of Medicine \\ Barbara Deloian, PhD, CPNP, IBCLC \\ Special Kids, Special Care, Inc \\ Linda Wollesen, BSN, MA, LMFT \\ Director, Life Skill Outcomes, LLC
}

\begin{abstract}
The NICU experience impacts all family dynamics not just during the intensive care unit stay but in the months and years afterwards. For each family, the first experiences with their baby, whether in the home or the intensive care unit, can set the trajectory for the long-term parent-child relationship and the parent's perspective of their parent roles. These difficult experiences have the potential to be addressed through infant and early childhood mental health (I/ECMH) methods. In this article we review the need for a wide range of social and emotional supports that present in intensive care and continue as families and infants transition to home and community. The potential for addressing these ongoing issues by a variety of providers within many different settings using Infant and Early Childhood Mental Health (I/ECMH) approaches is discussed and examples of successful programs are provided. Finally, we make recommendations for infusing I/ECMH across programs that serve intensive care unit graduates and their families, from the hospital, to the home, primary care providers, and other community support programs.
\end{abstract}

Key terms: home visiting; infant and early childhood mental health; reflective practice

This is the author's manuscript of the article published in final edited form as:

Tomlin, A. M., Deloian, B., \& Wollesen, L. (2016). Infant/Early Childhood Mental Health and Collaborative Partnerships: Beyond the NICU. Newborn and Infant Nursing Reviews, 16(4), 309-315. https://doi.org/10.1053/j.nainr.2016.09.025 
Running head: I/ECMH in NICU

\section{Infant/Early Childhood Mental Health and Collaborative Partnerships: Beyond the NICU}

\section{Introduction:}

In the United States significant efforts have been made to reduce the incidence of premature births and the long-term sequelae. However, despite these efforts each year in the United States about 500,000 babies are still born premature (less than 37 week's gestation or less than 2500 grams) or medically fragile with special health care needs such as congenital and genetic conditions (March of Dimes, Peristats, 2015). As a result of these and other conditions and circumstances, as many as 10 to $15 \%$ of babies in the United States require treatment in the Neonatal Intensive Care Unit (NICU) (Martin, Hamilton, Ventura, Osterman, Wilson \& Matthews, 2010). It is known that a prematurity is more likely in African American (16.5\%), Native American (13.4\%), Hispanic (11.5\%), and Asian (10.1\%) populations, versus Caucasian (10.3\%) (March of Dimes, Peristats, 2015). Across populations, modern medical technology has allowed smaller and smaller babies to survive; many of these infants do very well, despite their early neonatal course. However, many more of these babies are at immediate risk for mortality and morbidity (CDC, 2012), and attention to these urgent issues is the primary focus in the NICU (Purdy, Craig, \& Zeanah, 2015).

Over the long term, the medical, developmental, and behavioral challenges that affect these babies also affect their families in every conceivable way. The babies themselves are at risk for higher rates of persistent developmental and behavioral problems and other health concerns compared to their full term and less medically involved counterparts (Boss \& Hobbs, 2013; Hornman, de Winter, Kerstjens, Bos, \& Reijneveld, 2016). Furthermore, problematic infant developmental, behavioral, and physical outcomes may be exacerbated by many additional factors, including a variety of family risks. Examples of risks facing families include parental unemployment, young parent age, low parent education, parental addiction and mental illness, and living at poverty levels (AAP, Committee on the Fetus and Newborn, 2008; Weck, Paulose, \& Flaws, 2008). All of these risk issues--whether medical, social, or behavioral-need attention in order for babies to thrive and reach their potential. 
Running head: I/ECMH in NICU

The parents of premature and medically fragile infants are also under stress as a result of an intensive care unit stay for their baby. Parents of these babies are likely to experience greater emotional stress, depression, and uncertainty about their baby's future, as well as financial stress than do parents of term infants (Blackburn, 2010; Boyova, Kenner, 2012; Fraley, 1989; Gennaro, Grisemer, Musci, 1992; Purdy, Craig, \& Zeanah, 2015). Examples of parental stress related to hospital experiences include "the sudden nature of the situation, the separation from the child, and the lack of information concerning the prognosis" (Habersaat, Pierrehumbert, Forcada-Guex, Nessi, \& Ansermet, 2014, p. 458; Singer, Salvator, Guo, Collin, Lilien, Baley, 1999). It is important to recognize that the intensive care experience is not uniform and that family responses differ. For example, families expecting their first baby and anticipating a healthy newborn differ from those who have experienced a previous pregnancy loss. A refugee family who has escaped the terror of their war torn county may respond differently than a teen mother without any support systems. A parent with a history of drug use and child protective service encounters may have different expectations and reactions than a parent who has not had these life experiences. Therefore, a range of approaches, services and supports are needed, but not always available.

The intensive care unit experience impacts all family dynamics not just during the hospital stay but in the months and years afterwards. For each family the first experiences with their baby whether in the home or the hospital can set the trajectory for their long term parent-child relationship and the parent's perspective of their parent role. Parents of premature infants have expressed that they did not want to be a "member of that club" meaning, for example, a "NICU mom." They are less likely to join typical parent support groups such as La Leche as they feel their experience and their infants are different. Upon discharge from intensive care one of the first desires for parents is to "normalize" family life (Deloian, 1998, pp 142). Despite desiring normalcy they remain constantly worried and search for warning signs of impending illness or other physical or developmental complications.

Although intensive care unit staff work very hard to prepare families for the eventual discharge of their baby, these types of stressors may persist after the baby and family graduate from the hospital. Today most NICUs are more family oriented than in years past and there is every effort to begin 
Running head: I/ECMH in NICU

discharge teaching soon after admission (Murch \& Smith, 2016, this issue). However, families continue to report that despite all their preparation once they are home their baby's behavior and their own experience is not the same as while they were in the hospital. Parents have said, "Discharge from the NICU is like being placed on a raft in the middle of the ocean without oars" (Goyer, 2014).

When parents experience stress from the intensive care experience or other sources, depression and trauma symptoms may develop or be exacerbated, interfering with parents' ability to respond to their babies in ways that form healthy and nurturing relationships (Brahm, Cortazar, Fillol, Mingo, Vielma, \& Aranguiz, 2015; Cummings \& Davies, 1994; Tough, Siever, Leew, Johnston, Benzies, \& Clark, 2008; Sutter-Dallay, Dequae-Merchadou, Dlatigny-Dallay, Bourgeois, \& Verdoux, 2011). This is concerning, as a positive relationship between the parent and infant supports healthy social and emotional functioning, and is understood to form the foundation for gains in all other areas of development (Slater, Navqvi, Andrew, \& Haynes, 1987; Spittle, Anderson, Lee, Ferretti, Eeles, Orton, et al., 2010). Furthermore, neonatal risk factors may interact with parent emotional status and stress reactions as well as with preexisting parent and family risk factors. The mix of difficult personal circumstances and reactions may keep parents from providing what doctors and other health professionals say that vulnerable babies need to grow and develop (Browne, 2011). In some cases, the quality of the parent and child relationship may be compromised, increasing the chances that the baby will suffer negative outcomes (Browne, 2011; Reinson \& Bauman, 2009), reducing the effectiveness of the parent-child relationship as a source of regulation and buffer for stress, and resulting in further insults to the growing parent-child relationship (Boss \& Hobbs, 2013; Gerstein \& Poehlmann-Tynan, 2015). Over time, ongoing stressors and child and parent characteristics continue to interact and contribute to a range of relationship problems and child behavior issues that carry into later childhood and even beyond.

Psychosocial aspects of infant intensive care experience have traditionally received less attention than the child's immediate medical needs. This is unfortunate, as attention to relationships is central to the work that we do with very young children and their families (Achenbach, Howell, Aoki, \& Rauh, 1993); Boukydis, 2012; Fitzgerald, Weatherston, \& Mann, 2011; Benzies, Magill-Evans, Hayden \& Ballantyne 
Running head: I/ECMH in NICU

2013; Melnyk, Feinstein, Fairbanks, Schultz-Czarniak, Hust, et. al., 2006). Attention is needed to the parent's responses and reactions to the potentially traumatic experience of having a medically fragile or premature infant who needs intensive treatment; to the experience of the baby under these circumstances; and to the parent and child relationship (Boukydis, 2012; Weatherston, 2000; Fitzgerald et al., 2011). Among the most vitally important methods of responding to the wide range of problems these babies and their families may experience both in intensive care and upon their transition home are the services and approaches that stem from an infant and early childhood mental health (I/ECMH) perspective (Boukydis, 2012; Reinson \& Bauman, 2009).

Within the scope of I/ECMH, interventions include a range of services and supports that are delivered by many different professionals beginning before pregnancy and continuing into the postpartum period. Home visitors, nurses, early intervention therapists, and mental health providers are just some of the professionals whose work may fall under the umbrella of I/ECMH informed work. Services may be provided to families in their homes, in hospitals and in outpatient settings and range from promotion of positive relationships, prevention of problems in at-risk populations, and intervening when significant concerns are present. The following discussion will describe I/ECMH, review its effectiveness with families that have experienced intensive care, discuss the barriers and opportunities that prevent families from accessing the services, review some examples of successful programs, and provide recommendations for practice and policy for coordinated supports for referral, follow-up, and effective intervention strategies.

\section{NICU and I/ECMH}

It is clear that premature birth or other medical issues that result in admission to newborn intensive care and the intensive care stay itself may affect parents and babies in ways that can be addressed with I/ECMH informed interventions (Boukydis, 2012; Browne \& Talmi, 2012; Reinson \& Bauman, 2009). Several key categories of support for parents with babies in the NICU have been identified that are well aligned with I/ECMH practice. These include parent emotional support, parent 
Running head: I/ECMH in NICU

education, and child development support (Benzies, Magill-Evans, Hayden \& Ballantyne, 2013; Purdy, Craig, \& Zeanah, 2015).

I/ECMH interventions have been shown to result in changes in parent-child interactions, parental mental health status, and child behavior and physiological status in the population of newborn intensive care unit graduates. For example, a recent randomized controlled trial demonstrated the effectiveness of Interaction Guidance, a video based method of increasing parental sensitivity, with parents of premature infants while in the NICU (Hoffenkamp, Tooten, Hall, Bracken, Eliens, Vingerhoets, et al., 2015). Although parental stress and intrusive behaviors were not reduced, increases were found in parental sensitivity and reductions were found for behaviors consistent with withdrawal. In another a recent study, parents of pre-term infants participated in an intervention designed to promote parental responsiveness and sensitivity. A physiological marker of stress, diurnal cortisol levels in the treated group were more similar to that of term babies, while pre-term babies without the intervention were significantly different (Habersaat, et al., 2014).

\section{Barriers to Infant/Early Childhood Mental Health Practice}

Despite the plethora of evidence for the effectiveness of I/ECMH methods, there continue to be a number of barriers to accessing and integrating I/ECMH practice into programs serving young children in general, and specifically into settings that serve medically fragile babies and their families. These barriers may be present at all times and locations in the service delivery system: crossing the continuum of service locations and types and occurring at all times from pre-conception to release from intensive care and transition into community services (Little, Kamholz, Corwin, Barrero-Castillero, \& Wang, 2015). Action is needed at all levels, including identification, referral and access to service.

Initial identification of parents and babies with needs that can be addressed through I/ECMH methods is lagging. Challenges to implementing prenatal screening include poor consistency and implementation of screening due to staffing issues, a lack clinical systems to provide the screening, 
Running head: I/ECMH in NICU

limited time to counsel mothers should the screening reveal that there is a risk of PRD, and lack of knowledge about mental health community resources for referral.

In the world of preterm births and NICU care, families and preterm infants are often either followed by home or center-based child development programs on discharge or are lost to follow up due to inadequate interagency referral practices or family chaos. Although there is recognition that NICU survivors may have developmental and behavioral issues, identification of the delays with appropriate referral and entry into services is not guaranteed (Keller-Margulis, et al., 2013). This could be due to providers such as hospital based staff or primary care providers (PCPs) prioritizing survival and not having behavior and development on their radar. The issue continues to be a concern as infants transition from intensive care to home. Despite long-standing best practices guidelines from professional organizations, including the American Academy of Pediatrics (AAP, 2008) and others, primary care providers frequently fail to perform screening for developmental delay and screening that specifically addresses social and emotional areas is even less likely to occur (Greene \& Patra, 2016; Weitzman, \& Wegner, 2015).

This is particularly worrisome for the approximately $75 \%$ or 375,000 late preterm infants (over 1200 grams or between 34 6/7 weeks and 36 6/7 weeks and 33-34 weeks gestation) who do not meet Part C of the Individuals with Disabilities Education Act (IDEA, 2004) eligibility or do not appear to have immediate needs for care (National Perinatal Association Steering Committee, 2012). Approximately $28 \%$ of these infants develop feeding, sleep, regulatory, motor, language, or social emotional issues later on in infancy, or behavior concerns in the toddler or preschool period (Greene \& Patra, 2016). Due to a lack of screening in general, these higher-risk babies may not receive ongoing screening through their primary care providers that could identify a delay once it appears or they may be lost to follow-up entirely (Greene \& Patra, 2016).

Furthermore, even when a child does qualify for Early Intervention (EI) programming, services may not be received. As many as $70 \%$ of babies born pre-term qualify for EI. However, actual utilization rates are often much lower (Keller-Margulis, et al., 2013). In one study, $72 \%$ of pre-term children with 
Running head: I/ECMH in NICU

mild delays were not in services by 2 years and about $50 \%$ of those with moderate to severe disabilities had not received services at age 2 years (Roberts, Howard, Spittle, Brown, Anderson, \& Doyle, 2008). It is worth noting that the most likely services to be accessed by this population include attention to motor delays (i.e., OT and PT). Services that address behavior, parent-child relationships, or other social and emotional aspects of development are rarely accessed through Part C early intervention despite these behavioral and social and emotional issues being included in the federal law. In one sample of EI usage by high risk children, most were receiving physical, occupational and speech therapies, whereas virtually no families received social work supports (Keller-Margulis, et al., 2013).

Parents and professionals alike may be unaware of the need to support a baby from a social and emotional perspective, or that capacity in these areas affects other types of development. Providers may fail to screen and refer due to the belief that there is nothing that can be done or that a service is unavailable. Furthermore, both parents and professionals may hold negative views or beliefs about mental health services, leading to reluctance to participate even when services are available.

Once a need is identified and a family is receptive to a service, providers and families may struggle to identify an appropriate referral source. Despite inclusion of mental health services in the Affordable Care Act, availability of mental health providers for all ages is severely limited across the U.S. (Mental Health America, 2015). The paucity of providers and services is especially acute for families of infants and young children when the provider must be familiar with the mental health and developmental issues of the mother, infant, father, and overall family dynamics (Melnyk, Oswalt, \& Sidora-Arcoleo, 2014; Pichler-Stachl, Pichler, Granmm, Zotter, Mueller, \& Urlesbewrger, 2011; Weatherston, 2005). At times this lack of experienced providers may mean that parents are referred to inappropriate services, with providers who do not have the knowledge and skills needed to form a relationship that supports an intensive care unit graduate and her family. Families can become frustrated and providers may be hesitant to make future referrals. 
Running head: I/ECMH in NICU

Families with a premature or medically fragile infant are among the most likely to have the greatest additional challenges to basic needs and other psychosocial risk factors. These risk factors include challenges in meeting basic needs (e.g., housing, clothing, food, transportation, income), a history of trauma, or parental mental health diagnosis or an addiction, that may interfere with the parent's ability to accept and benefit from I/ECMH services and which may negatively impact child development and the parent-child relationship (Teeters, et al., 2016). These families are also likely to lack access to mental health services that would help the infant and caregiver discharged from the intensive care unit (Subramanian, Katz, Rodan, Gantz, El-Khorazaty, Johnson, 2012). Although supports may be available, parents who experience identified risk factors are less likely to be connected with needed community resources or to follow through with referrals.

Upon discharge from intensive care units, families often receive numerous referrals to their primary care provider, medical specialist, home health care, in-hospital therapist, early intervention (when eligible) and in some communities to public health home visitation programs and supports. The challenge for families is keeping track of these referrals, scheduling appointments, and arranging transportation and for selected families, translation services. Families must cope with multiple systems, which requires coordination and collaboration. Each provider or system frequently has different requirements, expectations, rules and processes. Often families simply decide to defer particular services rather than attempting to become the coordinator of all the coordinators who are trying to assist them. The result is that the family may fail to follow-up with certain supports because they do not understand the purpose and value for their child and family (Ballantyne, Stevens, Guttmann, Willan, \& Rosenbaum, 2014).

For some families, court or child protection services (CPS) involvement creates an additional layer of complexity. For example, CPS can become involved prenatally or at delivery if there is evidence that the infant was substance exposed in utero. CPS workers may also be involved if there is evidence of abuse or neglect at any time, or in some states when young children are present when domestic violence occurs. The chances of abuse and/or neglect are high for younger babies in general. Those children with 
Running head: I/ECMH in NICU

developmental and behavioral problems are more than 3 times as likely to be the victims of abuse or neglect as others (Sullivan and Knutson, 2000).

\section{Using I/ECMH Practices in Home Visiting Settings}

Expanded roles. Despite much progress, the community based referral systems and the crossdiscipline knowledge of the concepts and use of I/ECMH services has not yet reached its full incorporation into the continuum of care, often because many communities lack appropriate I/ECMH services. In response to this need, there is increasing recognition that home visiting services are a viable way of providing a large range of services to young families, ranging from prevention to intervention (Stark, Gebhard, \& DiLauro, 2014). These services are even more important in places where other services are less available. Recent research has focused on increasing the skills of home visitors to perform screening, referral, and even some level of intervention with difficult issues including maternal depression and trauma (Ammerman, Putnam, Chard, Stevens, \& Van Ginkel, 2016); Fodstadt, 2012; Laszewski, Wichman, Doering, Maletta, and Hammel, 2016). Expanded services also include routine use of developmental screening (e.g., Ages and Stages Questionnaires-ASQ: Bricker \& Squires, 2009), depression screening (e.g., Beck \& Gables, 2002), assessment of life skills (Life Skill Progression-LSP Wollesen \& Piefer, 2006) and frameworks that support reflective practice (PAUSE, Tomlin \& Viehweg, 2016). This expansion of the home visitor role must balance the trust and comfort level many families have with the home visitor while maintaining awareness of the limits of this role (Wesley \& Buysee, 2001; Zeanah, Larrieu, \& Boris, 2006). This balancing act includes training home visitors in two key concepts borrowed from I/ECMH: relationship-based and reflective practices (Tomlin \& Viehweg, 2016).

Reflective practice. Because relationship and development are so interconnected, it is necessary for all professionals who support very young children and their families to have a working understanding of how relationship can promote and hinder development. In recognition of this, service delivery approaches in early childhood have long approached the work from relationship-based perspective 
Running head: I/ECMH in NICU

borrowed from mental health; this emphasis has been embraced by home visiting models including Healthy Families, Nurse Family Partnership, Head Start and Early Head Start, Parents as Teachers, Part C and other programs (Fodstadt, 2012; Institute of Medicine \& National Research Council, 2015; Paulsell, Avellar, Sama Martin, \& Del Grosso, 2011). Training for home visitors in relationship-based approaches is now expected for funded programs and is more and more available.

In concert with the use of relationship-based methods, many home visiting models also stress another "cross-over" mental health concept, reflective practice. Reflective practice is a way of working that includes slowing down, stepping back, and thinking more broadly about what is happening within encounters with families (Brandt, 2014). A distinction is made between reflecting after the fact, either on one's own or with a trusted mentor ("reflecting on action") and reflective practice which occurs when the provider is able to use reflection when actively working with a family ("reflecting in action") (Brandt, 2014; Schön, 1983, 1987).

Underlying the ability to be reflective in practice is reflective functioning, or the ability to consider one's own inner experience and that of others and to connect these inner experiences with overt behaviors (Fonagy, Steele, Moran, Steele, \& Higgitt, 1991; Fonagy, Gergely, Jurist, \& Target, 2002; Slade, 2005). Providers should both demonstrate reflective skills and seek to enhance these skills in parents. Specifically, building the reflective functioning skills of parents is often emphasized within family support fields as a way to support the parent-child relationship and child development (Slade, 2006). When parents are able to consider and attend to their young child's experience, a secure attachment is more likely to form and learning is facilitated; the process can also serve to repair relationships when needed (Fonagy \& Target, 2005; Sadler, Slade \& Mayes, 2006). As a result, reflective function has been thought of as a core function of parenting (Slade, 2005).

Smith and Wollesen (2011) provide a simplified way of summarizing parental reflective functioning in a 3-step rubric "Think, Link and Respond" that can be used by a variety of providers in practice. In this model a parent is encouraged to Think about and put words to behavior, feelings, 
Running head: I/ECMH in NICU

relationships, events, and consequences; Link these perceptions to information that is needed or already known; and Respond with a plan of action. Professionals can learn to notice when a parent demonstrates or is frequently unable to use specific reflective functioning skills. A parent can demonstrate reflective functioning skills when able to able to conceptualize and put into their own words "Think-Link-Respond" steps. In contrast, parents with limited reflective skills can be recognized because they fail to think, link, and respond in a logically useful way, have inadequate information to draw conclusions from what they observe, misinterpret situations, show decreased ability to weigh their needs and response options, are limited by low self-confidence, or fail to carry out plans they make.

Providers can help parents achieve these skills through the use of reflective questions that "teach by asking". Reflective questions set up a discovery process that can be directed at most life situations like health care, parenting and life skill issues. The parent owns their answers so appropriate action is more likely. Initial reflective questions should focus on the Think categories first before moving to linking questions or a plan of action, because without this perception base the parent has not discovered a reason for moving beyond a circumstance needing attention. An example of a simple thinking question is "How do you feel about getting ready for your baby coming home?” This question could be followed by additional thinking questions, such as "What are the care items that you feel comfortable and confident about and which are you worried about?" Alternatively, the worker could prompt for information with a linking question, such as "Would you like me to give you more information about Parents as Teachers services?" Plan questions are also utilized, such as "You told me how depressed you were about the baby's father rejecting you both; have you considered whether talking to someone about this might help you and make it easier to get to a happier place?" It is important not to give a parent the answer, and to simply let them continue to think about it.

Reflective questions can be used to help a parent recognize their own strengths in order to develop self-confidence and better notice and meet their own needs and those of their infant. Examples of areas where reflective questions may be more powerful than advice or information are in relationships, attachment and bonding, child development, co-regulation and self-regulation, cognitive and psychosocial 
development and life skill development needed to move out of poverty and establish a satisfying life style. As parents increase in their use of the Think-Link-Respond method, they can also begin to teach reflective skills to their own children. Therefore, the approach potentially impacts the life skills of two generations as workers carry out their primary professional roles across the continuum of services from the intensive care unit, to EI or early childhood home visitation and I/ECMH. Table 1 provides examples of use of reflective questions in different service environments and situations.

Table 1: Think-Link-Respond Examples for Home Visitors

\begin{tabular}{|c|c|c|c|}
\hline $\begin{array}{l}\text { Parent or Infant } \\
\text { Situation }\end{array}$ & $\begin{array}{l}\text { Strength or Need } \\
\text { Focus }\end{array}$ & $\begin{array}{l}\text { Sample Reflective } \\
\text { Question }\end{array}$ & $\begin{array}{l}\text { Possible Parental Reflective } \\
\text { Response }\end{array}$ \\
\hline $\begin{array}{l}\text { NICU: parent } \\
\text { overstimulates } \\
\text { infant and seems } \\
\text { frustrated }\end{array}$ & $\begin{array}{l}\text { Wants a } \\
\text { relationship and } \\
\text { response; } \\
\text { Needs } \\
\text { information on } \\
\text { cues, infant } \\
\text { needs and ways } \\
\text { to support infant } \\
\text { responses }\end{array}$ & $\begin{array}{l}\text { "I can see you really } \\
\text { wanted your baby to } \\
\text { respond to you,. What did } \\
\text { you see him doing? } \\
\text { "“"Have you notices times } \\
\text { when he responds are } \\
\text { more focused? What was } \\
\text { different?" } \\
\text { "Would you like } \\
\text { information on how to see } \\
\text { your baby's different } \\
\text { responses?" }\end{array}$ & $\begin{array}{l}\text { "I did...I am just so relieved } \\
\text { that he is alive." } \\
\text { "He didn't seem to like what } \\
\text { I was doing and just shut } \\
\text { down." } \\
\text { "I want to be able to } \\
\text { understand and comfort him } \\
\text { better." }\end{array}$ \\
\hline $\begin{array}{l}\text { EI: grieving } \\
\text { about baby } \\
\text { needing outside } \\
\text { help }\end{array}$ & $\begin{array}{l}\text { Wants her baby } \\
\text { to be OK; afraid } \\
\text { of being told } \\
\text { what to do. } \\
\text { Terrified that her } \\
\text { baby has special } \\
\text { needs. }\end{array}$ & $\begin{array}{l}\text { "When you were referred } \\
\text { to EI what did they tell } \\
\text { you about the services?" } \\
\text { "When you think about } \\
\text { how relieved you are now } \\
\text { that your baby is finally } \\
\text { home, what you want for } \\
\text { him now... what are some } \\
\text { of the things you hope he } \\
\text { will be able to do?" } \\
\text { "How is he doing with } \\
\text { feeding?" }\end{array}$ & $\begin{array}{l}\text { "They told me that my baby } \\
\text { had bad vision and cerebral } \\
\text { palsy, and that he would need } \\
\text { help developing. I just wanted } \\
\text { him to be home and be OK." } \\
\text { "What's this EI gonna be } \\
\text { like? How's it gonna make } \\
\text { my baby better?" } \\
\text { "He chokes a lot and keeps } \\
\text { falling asleep... } \\
\text { I think he listens when I } \\
\text { sing." }\end{array}$ \\
\hline $\begin{array}{l}\text { Home Visitation } \\
\text { ECE: happy to } \\
\text { be home but } \\
\text { scared about } \\
\text { caring for } \\
\text { baby...not sure } \\
\text { who to turn to for } \\
\text { help. Unaware } \\
\text { of what parent } \\
\text { education } \\
\text { services are. }\end{array}$ & $\begin{array}{l}\text { Wants to be a } \\
\text { good mother } \\
\text { Open to } \\
\text { information and } \\
\text { help learning }\end{array}$ & $\begin{array}{l}\text { "Would you like to see } \\
\text { some of the information I } \\
\text { brought for you about...?" } \\
\text { "What are some things } \\
\text { you have questions about } \\
\text { ?" } \\
\text { "Who do you turn to when } \\
\text { you are not sure what to } \\
\text { do for her?" }\end{array}$ & $\begin{array}{l}\text { "Sometimes she wakes up } \\
\text { screaming ...do you have } \\
\text { information about how to } \\
\text { comfort her? Or what might } \\
\text { be going on?" }\end{array}$ \\
\hline
\end{tabular}




\begin{tabular}{|l|l|l|l|}
\hline $\begin{array}{l}\text { IMH: } \\
\text { pediatrician } \\
\text { suggested IMH } \\
\text { for a toddler who } \\
\text { is into everything } \\
\text { and mad a lot }\end{array}$ & $\begin{array}{l}\text { Overwhelmed by } \\
\text { son's being into } \\
\text { everything; mad } \\
\text { at him because } \\
\text { he never listens } \\
\text { or stops }\end{array}$ & $\begin{array}{l}\text { "Can you remember a } \\
\text { time when you were able } \\
\text { to get him interested in } \\
\text { something else?" } \\
\text { "Have there been other } \\
\text { times when distracting } \\
\text { him works? When do you } \\
\text { notice him slowing down } \\
\text { and being more settled?" }\end{array}$ & $\begin{array}{l}\text { offered him a drink of juice, } \\
\text { and he stopped kicking the } \\
\text { cabinets. " } \\
\text { "Now that I think of it, there } \\
\text { have been a couple of times } \\
\text { when I offered him something } \\
\text { else to do. Sometimes when } \\
\text { we sing together he settles } \\
\text { down." }\end{array}$ \\
\hline
\end{tabular}

Partnering with caregivers. In order to successfully use relationship-based practice and reflective methods, early intervention professionals often need to expand their role concept from someone who directs care, gives information and teaches as the expert, to a partner who supports the parent to think more broadly, notice things, reach conclusions and think of a response. This shift requires that providers follow a similar pathway, using thinking, linking and planning themselves. Learning to think about their own, the parent's and the infant's experience can take time and support. Providers must consciously work to recognize opportunities to use a reflective question, for example. Programs can provide their professional staff with a written list of sample reflective questions in order to increase their vocabulary of possible questions. Teams can use staff meetings to brainstorm sample questions and share successful examples of reflective questions used with a family. Supervision or consultation that supports reflective skill and practice of the provider are often recommended. With practice it is realistic to expect staff to be able to spontaneously use reflective questions and other reflective methods on a regular basis as they work with families.

\section{Recommendations for Practice and Policy for Increasing the Use of I/ECMH Within and Beyond the NICU}

We have reviewed the need for a wide range of supports for the social and emotional issues that present in the intensive care unit and continue as families and their infants transition to home and community. There is potential for a variety of providers within many different settings to effectively respond to these family needs, reducing barriers to access. In the following section we provide 
Running head: I/ECMH in NICU

recommendations for improving services more globally for intensive care graduates and their families along with examples of successful programs.

\section{Recommendation \#1: Ensure continuity of care through better communication and coordination across systems}

Several national organizations provide guidelines that define best practices in the discharge and follow up of vulnerable premature and medically fragile infants that include significant levels of preplanning, communication, coordination, and feedback (Murch \& Smith, 2016, this issue). These include the American Academy of Pediatrics Committee on Fetus and Newborn (2008), the March of Dimes (Bakewell-Sachs \& Blackburn, 2012), Agency for Healthcare Research and Quality (AHRQ) (2013), National Institute for Children's Healthcare Quality (NICHQ) (Ariagno\& LaBella. 2012) and the National Association of Neonatal Nurses (NANN) (2014). This level of system building will require a high level of interdisciplinary care and partnership that must begin in the hospital intensive care unit.

Examples of strategies that can improve coordination of care as infants transition to communities include: increasing referrals of NICU graduates who do not show an immediate need to home visiting programs that can provide monitoring and follow-up; providing opportunities for parents to meet with staff from community programs prior to discharge; and developing mechanisms for sharing records and information across systems so that all supporting professionals and parents are fully informed. The Arizona Smooth Way Home Program is an example of a thriving effort to support the successful transition for fragile infants and their families from the newborn intensive care unit back to their community through communication and collaboration between and among hospital NICU staff, early intervention, public health, and other community parent support programs. (https://www.swhd.org/). Efforts are underway to demonstrate program effectiveness through increased parent referral, followup and reduction of parental stress and pregnancy related depression.

As part of a full range of resources for vulnerable infants and their families, I/ECMH services and supports must be represented. As discussed, intensive care graduates and their families have many needs 
Running head: I/ECMH in NICU

that can potentially be addressed through I/ECMH methods implemented by a range of professionals. Better awareness of the signs and symptoms of mental health concerns in parents and babies, ongoing and routinely implemented screening for both, and provision of a range of services from promotion to intervention that starts in the hospital and continues during transition to community settings are all necessary. Recent trends in co-location and integration of mental health services in primary care provide more opportunity for these partnerships (Collins, Hewson, Munger \& Wade, 2010; Williams, Schore, \& Foy, 2006).

\section{Recommendation \#2: Continue to build common language, knowledge, and skills related to the needs of families whose baby has been in the NICU across a variety of provider types}

Family service providers across discipline lines and service environments have become aware of information and specialized practices needed for intensive care graduates. Similarly, we have seen that a multitude of types of provider can learn and use I/ECMH methods as part of their practice with this population. This shared information, including reflective and relationship-based practices, knowledge of child development, use of age-adjusted screening tools, and awareness of the effects of immature neurology on parent/child relationships and child development, has been added to the community level of care, along with the need for early intervention and developmental criteria for referral.

Various methods are needed to build a sufficient workforce with the above knowledge and skill to address the needs of these fragile babies and their parents. Distance and asynchronous methods of training such as webinars can allow for increased access to information for continuing education. Recent books provide templates for providers seeking to learn through self-study (e.g., Coming Home from the NICU, VandenBerg \& Hanson, 2013). Beyond gaining knowledge, however, providers must also increase their abilities to apply this learning. Collaborative learning opportunities, including mentoring and reflective consultation methods should be built into workforce development plans. An example of a competencybased approach that combines supervision/consultation with knowledge is the Infant Mental Health Endorsement developed by the Michigan Association for Infant Mental Health and now functioning in more than 20 other states (Weatherston, Kaplan-Estrin, \& Goldberg, 2009). 
Running head: I/ECMH in NICU

An example of a program that combines many of these suggestions, including incorporation of I/ECMH concepts with specialized knowledge about very young babies with special needs is the BABIES Model (Browne \& Talmi, 2012). The BABIES model utilizes a collaborative approach to build on the skills of working early intervention professionals. The training program increases participant knowledge and skills needed to successfully assess and intervene with these babies and their parents, allowing them to address common problem areas including sleep, eating, and interactions, among others. Early outcomes include increases in knowledge and change in practice through self-report (Browne \& Talmi, 2012).

\section{Recommendation \#3: Increased Acceptance of Home Visitation as a Complementary Model of Care for Infants and Toddlers Through Collaborative Outcome Studies.}

As discussed, despite a high level of need for pediatric mental health supports in general and in NICU graduates specifically, access to services continues to be challenging. Increasingly, communities turn to home visitors to provide supports to highly vulnerable families. Importantly, providing I/ECMHinfused services as part of home visiting has many advantages. Families are likely to trust their providers, leading to longer participation in services. Providing services in the home avoids many of the barriers that families report, including lack of transportation. When services occur at home, providers can see how things really are for families; as a result, parents may be more likely to apply information that is shared as it is more meaningful. As training improves and skill levels of home visitors rise, it is increasingly appropriate to view home visitation as a source of mental health promotion and to some degree, intervention, when provided in partnership with mental health professionals.

Acceptance of the utility of home visitation to address more complex issues will continue to grow as training improves and evidence for effectiveness mounts. Demonstrating program effectiveness through collaborative research and outcome studies across disciplines and across settings will provide the evidence needed to fund and sustain programs that support the social and emotional needs of families and infants as they transition from the NICU to their home and community. Progress has already been made as several studies have demonstrated effectiveness of home visiting on a range of parent and child 
Running head: I/ECMH in NICU

outcomes (Olds, Holmberg, Donelan-McCall, Luckey, Knudtson \& Robinson, 2014; Paulsell, Avellar, Sama Martin, \& Del Grosso, 2011). For example, in a number of studies home visiting has been shown to reduce symptoms of parental depression with associated positive child effects (Evans, Whittingham, \& Boyd, 2012; Izzo, Eckenrode, Smith, Henderson, Cole, Kitzman, \& Olds, 2005; Laszewski, Wichman, Doering, Maletta, \& Hammel, 2016; Spittle, Anderson, Lee, Ferretti, Orton, Boyd, \& Doyle, 2010). More recently, there is support for adding attention to parental trauma symptoms as part of home visitation (Ammerman, Putnam, Chard, Stevens, \& Van Ginkel, 2016). Home visiting has also been shown to enhance parental health literacy after 12-18 months of participation resulting in statistically significant increases in parental ability to manage their own and their child's health care (Smith, 2010). A follow up study (Smith \& Moore, 2012) on maternal depression and health literacy showed that depression did not interfere with the home visitor's ability to promote maternal health literacy skills.

Several studies have examined the effect of home visiting on babies with NICU experience and those who are premature or born at low birth weight (for review, see Goyal, Teeters, \& Ammerman, 2013). Although the review indicated that parent-infant interactions were improved through the programs, Goyal and colleagues identified several gaps in the literature (2013). Most notably, they call for specific attention to issues related to the premature population, such as attention to gestational age, and more data on curricula that are tailored to the NICU graduate or premature infant. Collaborative research methods that allow providers to work across disciplines and settings would address these gaps in the literature. For example, the Vermont Oxford Network is a collaborative that has been active in producing data from randomized clinical trials aimed at common issues such as feeding, heat loss, and respiratory problems (https://public.vtoxford.org/research/trials/). A similar approach to evaluating evidence-based interventions for developmental, behavioral and relationship-focused problems in premature and other NICU infants and their families would be desirable. Current promising efforts include collaboration among clinicians and researchers around the country that are facilitated by Smooth Way Home and extension of the BABIES model to other states. 
Running head: I/ECMH in NICU

\section{Summary}

Although many families whose infants require NICU care are resilient, many others have significant and ongoing needs for supports and services. Multiple studies have confirmed the impact of the stressful intensive care unit experience on social and emotional well-being that may continue in the months and years afterward discharge. Fortunately there is an increasing awareness of hospital staff and community providers of the implications for families of an intensive care unit experience with regard to parental mental health, overall quality of family life and the health, development, and well-being of their infant who is already at risk for documented adverse medical and neurodevelopmental challenges.

Best practices in the care of these babies and families are highly aligned with the range of methods and supports that encompass the practices of infant and early childhood mental health. Increasingly infusing I/ECMH practices into the work of intensive care unit professionals and the full range of community providers across settings who receive these families will improve the coordination and quality of care needed to improve outcomes for these vulnerable babies and their parents. In order to maintain sustainability in this era of evidenced based practice it will be necessary to continue to specifically demonstrate the benefits and effectiveness of I/ECMH interventions when serving intensive care unit graduates. Much has been accomplished and much more remains to do. These examples of exemplary service provide a window into current and future possibilities for serving intensive care unit graduates and their families as they transition to home and community.

\section{References}

Achenbach, T. M., Howell, C. T. Aoki, M. F., \& Rauh, V. A. (1993). Nine-year outcome of the Vermont intervention program for low birth weight infants. Pediatrics, 91(1):45-55.

Agency for Healthcare Research and Quality (AHRQ). (2013). Transitioning Newborns from NICU to Home: A Resource Toolkit. AHRQ, Rockville, Maryland. Retrieved from: http://www.ahrq.gov/professionals/systems/hospital/nicu toolkit/index.html

American Academy of Pediatrics, Committee on Fetus and Newborn. Hospital discharge of the high-risk neonate. (2008). Pediatrics, 122(5): 119-1126.

Ammerman, R. T., Putnam, F. W., Chard, K. M., Stevens, J., \& Van Ginkel, J.B. (2016). PTSD in depressed mothers in home visitation. Psychological Trauma: Theory, Research, Practice and Policy, 4(2), 186-195. 
Running head: I/ECMH in NICU

Ariagno, R.L. \& LaBella, J.J. (2012). Toolkit for the Follow-up Care of the Premature Infant. MedImmune \& National Initiative for Children's Healthcare Quality (NICHQ). Boston, MA.

Bakewell-Sachs, S. \& Blackburn, S. (2012). Preterm infants: Transition to home and follow-up. March of Dimes Nursing Modules. White Plains, N.Y.

Ballantyne, M., Stevens, B. M. Guttmann, A., Willan, A.R., \& Rosenbaum, P. (2014). Maternal and infant predictors of attendance at Neonatal Follow-up Programmes. Child Care Health Development, 40(2), 250-8.

Blackburn, A. C. (2010). Stories, ethics and the interpretation of meaning: Bearing witness to mothers' stories of their neonatal intensive care unit experience (Order No. AAI3367164). Available from PsycINFO. (622195116; 2010-99020-117). Retrieved from http://search.proquest.com.ezaccess.libraries.psu.edu/docview/622195116?accountid=13158.

Barry, L.M. and Singer, G.H. (2001). Reducing maternal psychological distress after the NICU experience through journal writing. Journal of Early Intervention. 24(4), 287-297.

Beck, C.T. \& Gable, R.K., (2002). Post Partum Depression Screening Scale Manual, Western Psychological Services, Los Angeles CA.

Berns, S.D., Boyle, M.D., Popper, B., Gooding, J.S., the Preemie Health Coalition. (2007). Results of the premature birth national need-gab study. Journal of Perinatology. 27, S38-S44.

Benzies, K. M., Magill-Evans, J. E., Hayden, K. A., \& Ballantyne, M. (2013). Key components of early intervention programs for preterm infants and their parents: A systematic review and meta-analysis. BMC Pregnancy and Childbirth, 13, S10. Retrieved from http://dx.doi.org/10.1186/1471-2393-13$\underline{\mathrm{S} 1-\mathrm{S} 10 .}$.

Boykova M, \& Kenner C. (2012). Transition from hospital to home for parent of preterm infants. The Journal of Perinatal \& Neonatal Nursing; 26(1), 81-87.

Boukydis, Z. (2012). Collaborative consultation with parents and infants in the perinatal period. Baltimore: Brookes.

Boss, R. D. \& Hobbs, J. E. (2013). Continuity of care for NICU graduates. Contemporary Pediatrics. (http://contemporarypediatrics.modernmedicine.com/contemporarypediatrics/content/tags/american-academy-pediatrics/continuity-care-nicu-graduates).

Brahm, P. Cortazar, A., Fillol, M. P., Mingo, M.V., Vielma, C. Aranguiz, M. C. (2015). Maternal sensitivity and mental health: does an early childhood intervention programme have an impact? Family Practice, Retrieved from http://dx.doi.org/10.1093/fampra/cmv071.

Brandt, K. (2014). Transforming clinical practice through reflection work. In K. Brandt, B. Perry, S. Seligman, \& E. Tronick (Eds.), Infant and early childhood mental health: Core concepts and clinical practice (pp. 293-307). Washington, DC: American Psychiatric Association.

Bricker, D., \& Squires, J. (2009). Ages \& Stages Questionnaire (ASQ -3) A parent Completed Child Monitoring System. Paul Brookes Publishing, Baltimore MD.

Browne, J.V. (2003). New perspectives on premature infants and their parents. Zero to Three, 24(2), 4-12.

Browne, J. (2011). Developmental care for high-risk newborns: Emerging science, clinical application, and continuity from newborn intensive care unit to community. Clinics in Perinatology, 38(4), 719729. 
Browne, J. V., \& Talmi, A. (2012). Developmental supports for newborns and young infants with special health and developmental needs and their families: The BABIES Model. Newborn \& Infant Nursing Reviews, 12(4), 239-247.

Burnham, N., Feeley, N., \& Sherrard, K. (2013). Parents' perceptions regarding readiness for their infant's discharge from the NICU. Neonatal Network: The Journal of Neonatal Nursing, 32(5), 324-334. doi:10.1891/0730-0832.32.5.324.

Carter, J., Mulder, R., Bartram, A., \& Darlow, B. (2005). Infants in a neonatal intensive care unit: Parental response. Archives of Disease in Childhood - Fetal and Neonatal Edition, 90(2), F109F113.

Center on the Developing Child at Harvard University. (2016). Building core capabilities for life: The science behind the skills adults need to succeed in parenting and the workplace. Retrieved from: www.developingchild.harvard.edu.

Centers for Disease Control and Prevention (2012). Preterm Birth. Retrieved from cdc.gov/reproductivehealth/maternalinfanthealth/PretermBirth.htm.

Centers for Disease Control and Prevention. (2013). Mental Health Surveillance Among Children, United States 2005-2011, Morbidity and Mortality Weekly Report, 62(Suppl; May 16, 2013):1-35. Retrieved from http://www.cdc.gov/childrensmentalhealth/articles.html.

Collins, C., Hewson, D. L., Munger, R., \& Wade. T. (2010). Evolving models of behavioral health integration in primary care. New York: Milbank Memorial Fund.

Cummings, E.M., \& Davies, P.T. (1993). Maternal depression and child development. Journal of Child Psychology and Psychiatry, 35(1), 75-112.

Deloian, B.J. (1998). Caring Connections: Nursing support transitioning premature infants and their families home from the hospital. (Doctoral dissertation). Denver, CO: University of Colorado Health Sciences Center. Available from ProQuest Dissertations Publishing, 9911709. Retrieved from:

http://search.proquest.com.proxy.ulib.uits.iu.edu/pqdtglobal/docview/304482586/fulltextPDF/8E78 06B36B074543PQ/1?accountid=7398.

Duncan, G. J. \& Magnuson, K. (2013). Investing in preschool programs. Journal of Economic Perspectives, 27 (2) 109-132.

Egger, H. \& Angold, A. (2006). Common emotional and behavioral disorders in preschool children: Presentation, nosology, and epidemiology. Journal of Child Psychology and Psychiatry, 47, 313337.

Evans, T., Whittingham, K., \& Boyd, R. (2012). What helps the mother of a preterm infant become securely attached, responsive and well-adjusted? Infant Behavior and Development, 35(1), 1-11. doi:10.1016/j.infbeh.2011.10.002.

Fitzgerald, H. E., Weatherston, D. \& Mann, T. L. (2011). Infant mental health: An interdisciplinary framework for early social and emotional development, Current Problems in Pediatric Adolescent Health Care, 41, 178-182.

Felitti, V. J., Anda, R. F., Nordenberg, D., Williamson, D. F., Spitz, A. M., Edwards, V., et al. (1998). Relationship of childhood abuse and household dysfunction to many of the leading causes of death in adults. The Adverse Childhood Experiences (ACE) Study. American Journal of Preventive Medicine, 14(4), 245-258. 
Running head: I/ECMH in NICU

Forstadt, L. (2012). Home visiting and reflective practice: when systems change means practice change. Reflective Practice, 13(1), 97-114.

Fonagy, P., Steele, M., Steele, H., Moran, G. S., \& Higgitt, A. C. (19910. The capacity for understanding reflective states: The reflective state in parent and child and its significance for attachment. Infant Mental Health Journal, 12(3), 201-218.

Fonagy, P., Gergely, G., Jurist, E., Target, M. (2002). Affect Regulation, Mentalization and the Development of the Self. New York: Other Press.

Fraley, A.M. (1986). Chronic sorrow in parents of premature children. CHC. Fall. 15(2), 114-118.

Freeman, P. A. \& Clarkson. (2014). Prevalence and relationship between adverse childhood experiences and child behavior among young children. Infant Mental Health Journal, 35(6), 544-554.

Gardner, R., Li, Q., Baier, R.R., Butterfield, K., Coleman, E. A., \& Gravenstein, S. J. (2014). Is Implementation of the Care Transitions Intervention Associated with Cost Avoidance after Hospital Discharge? General Internal Medicine, 29(6), 878-84.

Gennaro, S., Brooten, D., Roncoli, M., \& Kumar, S.P. (1993). Stress and health outcomes among mothers of low-birth-weight infants. Western Journal of Nursing Research. 15(1), 97- 113.

Gennaro, S., Grisemer, A. and Musci, R. (1992). Expected versus actual life-style changes in mothers of preterm low birth weight infants. Neonatal Network. (3):39-45.

Gerstein, E. D., \& Poehlmann-Tynan, J. (2015). Transactional processes in children born preterm: Influences of mother-child interactions and parenting stress. Journal of Family Psychology, 29(5), 777-787.

Goyer, E. (2014). Personal communication, March 25, 2014.

Greene, M. \& Patra, K. (2016). Part C early intervention utilization in preterm infants: Opportunity for referral from a NICU follow-up clinic. Research in Developmental Disabilities, 53-54, 287-95.

Habersaat, S., Pierrehumbert, B., Forcada-Guex, M., Nessi, J., \& Ansermet, F. (2014). Early stress exposure and later cortisol regulation: Impact of early intervention on mother-infant relationship in preterm infants. Psychological Trauma: Theory, Research, Practice and Policy, 6(5), 457-464.

Hall, S., Cross, J., Selix, N., Patterson, C., Segre, L., Chuffo-Siewert, R., Martin, M. (2015a). Recommendations for enhancing psychosocial support of NICU parents through staff education and support. Journal of Perinatology, 35, S29-S36. doi:10.1038/jp.2015.146

Hall, S., Ryan, D., Beatty, J., \& Grubbs, L. (2015). Recommendations for peer-to-peer support for NICU parents. Journal of Perinatology, 35, S9-S13-S9-S13. doi:10.1038/jp.2015.143.

Health Resources and Services Administration. (2015). Maternal, Infant and Early Childhood Home Visitation Program: Partnering with parents to help children succeed. Retrieved from: www.mchb.hrsa.gov/programs/homevisiting.

Hoffenkamp, H., Tooten, A., Hall, R. A. S., Braeken, J., Eliens, M. P. J., Vingerhoets, A. J. J. M., \& van Bakel, H. J. A. (2105). Effectiveness of hospital-based Video Interaction Guidance on parental interactive behavior, bonding, and stress after preterm birth: A randomized controlled trial. Journal of Consulting and Clinical Psychology, 83(2), 416-429.

Holditch-Davis, D., White-Traut, R., Levy, J. A., O'Shea, T. M., Geraldo, V., \& David, R. J. (2014). Maternally administered interventions for preterm infants in the NICU: Effects on maternal 
psychological distress and mother-infant relationship. Infant Behavior \& Development, 37(4), 695710. doi:10.1016/j.infbeh.2014.08.005.

Hornman, J., de Winter, A. F., Kerstjens, J. M., Bos, A. F., \& Reijneveld, S. (2016). Emotional and behavioral problems of preterm and full-term children at school entry. Pediatrics, 137(5). DOI: 10.1542/peds.2015-225.

Hynan, M., Steinberg, Z., Baker, L., Cicco, R., Geller, P., Lassen, S., Stuebe, A. (2015). Recommendations for mental health professionals in the NICU. Journal of Perinatology, 35, S14S18. doi:10.1038/jp.2015.144.

Individuals with Disabilities Education Improvement Act. (2004). 20 USC 1400.

Institute of Medicine \& National Research Council. (2015). Transforming the workforce for children birth through age 8 years: A unifying foundation. Washington, DC: National Academies Press.

Izzo, C.V., Eckenrode J.J., Smith, E.G., Henderson, C.R., Cole, R., Kitzman, H., \& Olds, D.L. (2005). Reducing the impact of uncontrollable stressful life events through a program of nurse home visitation for new parents. Prevention Science, 6(4) 269-274.

Laszewski, A., Wichman, C. L., Doering, J. J., Maletta, K., \& Hammel, J. (2016). Perinatal depression algorithm: A home visitor step-by-step guide for advanced management of perinatal depression symptoms. Zero to Three, 36(4), 2-9.

Lefkowitz, D., Baxt, C., \& Evans, J. (2010). Prevalence and correlates of posttraumatic stress and postpartum depression in parents of infants in the neonatal intensive care unit (NICU). Journal of Clinical Psychology in Medical Settings, 3, 230-237. doi: 10.1007/s10880-010-92027.

Little, A. A., Kamholz, K., Corwin, B.K., Barrero-Castillero, A., \& Wang, C.J. (2015). Understanding the barriers to early intervention services for preterm infants: Lessons from two states. Academic Pediatrics, 15(4), 430-8.

Keller-Margulis, M. A., Abrahamson, C. W., Llorens, A. V., \& Dempsey, A. G. (2013). Early intervention service utilization among children born preterm. Clinical Practice in Pediatric Psychology, 1(4), 344-354. http://dx.doi.org/10.1037/cpp0000029.

Martin, J. A., Hamilton, B. E., Ventura, S. J., Osterman, M., Wilson, E. C., \& Matthews, T. J. (2010). Births: Final data for 2010. National Vital Statistics Report 61(2).

March of Dimes. (2015). Peristats. Premature Birth Report Card. Retrieved from: http://www.marchofdimes.org/peristats/Peristats.aspx.

Melnyk, B.M., Crean, H., Feinstein, N.F., Fairbanks, E. (2008). Maternal anxiety and depression following a premature infants' discharge from the NICU: Explanatory effects of the COPE Program. Nursing Research, 57(6), 383-394.

Melnyk, B.M. Feinstein, N., F., Fairbanks., F., Schultz-Czarniak, J. Hust, D. et.al. (2006). Reducing premature infants' length of stay and improving parents' mental health outcomes with the creating opportunities for parent empowerment (COPE) neonatal intensive care unit program: a randomized, controlled trial. Pediatrics. (2006) 118, e1414-e1427.

Melnyk. B.M., Oswalt, K.L., Sidora-Arcoleo, K. (2014). Validation and psychometric properties of the neonatal intensive care unit parental beliefs scale. Nursing Research, 63(2), 105-115. 
Running head: I/ECMH in NICU

Mental Health America. (2015). Parity or disparity: The state of mental health in America. Retrieved from http://www.mentalhealthamerica.net/sites/default/files/Parity\%20or\%20Disparity $\% 20$ Report $\% 20 \mathrm{FI}$ NAL.pdf.

Moore E. R., Anderson, G. C., \& Bergman, N. (2007). Early skin-to-skin contact for mothers and their healthy newborn infants. Cochrane Database System Review, Jul 18;(3):CD003519.

Murch, T. \& Smith, ?. (2016).

National Association of Neonatal Nurses (NANN). (2014). Baby Steps to Home: A Guide to Prepare NICU Parents for Home. Chicago, Illinois.

National Perinatal Association Steering Committee. (2012). Multidisciplinary Guidelines for the Care of Late Preterm Infants. National Perinatal Association.

National Institute of Children's Health Quality (NICHQ) (2016). Neonatal Outcomes Improvement Project (NOIP). Available from: http://www.nichq.org/childrens-health/infant-health/neonataloutcomes-improvement-projects.

Obeidat, H. M., Bond E. A., \& Callister, L. C. (2009). The parental experience of having an infant in the Newborn Intensive Care Unit. The Journal of Perinatal Education, 18(3), 23-29. Retrieved from http://doi.org/10.1624/105812409X461199.

Olds, D. L., Holmberg, J., Donelan-McCall, N., Luckey, D. W., Knudtson, M. D., \& Robinson, J. (2014). Effects of home visits by paraprofessionals and by nurses on children: Age 6 and 9 follow-up of a randomized trial. JAMA Pediatrics, 168(2), 114-121.

Paulsell, D., Avellar, S., Sama Martin, E., \& Del Grosso, P. (2011). Home Visiting Evidence of Effectiveness Review: Executive Summary. Office of Planning, Research and Evaluation, Administration for Children and Families, U.S. Department of Health and Human Services. Washington, DC.

Pichler-Stachl, E., Pichler, G., Granmm, S., Zotter, H., Mueller, W., \& Urlesbewrger, B. (2011). Prematurity: Influence on mother's locus of control. Wien Klin Wochenschr, 123(13-14) 455457.

Purdy, I. B., Craig, J. W., \& Zeanah, P. (2015). NICU discharge planning and beyond: Recommendations for parent psychosocial support. Journal of Perinatology, 35, S24-S28.

Reinson, C. \& Bauman, D. (2009). The Neonatal Intensive Care Unit. In Ensher, G. L., Clark, D. A., \& Songer, N. S. (Eds.), Families, infants, \& young children at risk (p. 319-334), Baltimore: Brookes.

Roberts, G. Howard, K., Spittle, A. J., Brown, N. C., Anderson, P. J., \& Doyle, L. W. (2008). Rates of early intervention services in very preterm children with developmental disabilities at age 2 years. Journal of Paediatrics and Child Health, 44, 276-280.

Rossman, B., Greene, M. M., \& Meier, P. P. (2015). The role of peer support in the development of maternal identity for "NICU moms". Journal of Obstetric, Gynecologic, \& Neonatal Nursing: Clinical Scholarship for the Care of Women, Childbearing Families, \& Newborns, 44(1), 3-16. doi:http://dx.doi.org.ezaccess.libraries.psu.edu/10.1111/1552-6909.12527.

Sadler, L. S., Slade, A., \& Mayes, L.C. (2006). Minding the baby: A mentalization-based parenting program. In J.G. Allen \& P. Fonagy (Eds.) Handbook of mentalization-based treatment (pp. 271288). New York: Wiley.

Schön, D. A. (1983). The reflective practitioner. New York: Basic Books. 
Schön, D. A. (1987). Educating the reflective practitioner. San Fransisco: Jossey-Bass.

Shonkoff, J. \& Phillips, D. A. (2000). From neurons to neighborhoods: The science of early childhood development. Washington, DC: National Academies Press.

Singer, L.T., Salvator, A., Guo, S., Collin, M., Lilien, L., and Baleny, J. (1999). Maternal psychological stress after the birth of a very low-birth-weight infant. JAMA, 281(9), 799-805.

Siu, A. L., and the US Preventive Services Task Force (USPSTF). (2016). Screening for Depression in Adults: US Preventive Services Task Force Recommendation Statement. JAMA, 315(4):380-387. doi:10.1001/jama.2015.18392.

Slade, A. (2005). Parental reflective functioning: An introduction. Attachment \& Human Development, $7(3), 269-281$.

Slade, A. (2006). Reflective parenting programs: Theory and development. Psychoanalytic Inquiry: A Topical Journal for Mental Health Professionals, 36(4), 640-657.

Slater, M.A., Navqvi, M., Andrew, L., \& Haynes, K. (1987). Neurodevelopment of monitored versus nonmonitored very low birth weight infants: the importance of family influences. Journal of Developmental and Behavioral Pediatrics, 8(5), 278-85.

Smith, S., \& Moore, E. J. (2012). Health literacy and depression in the context of home visitation. Maternal and Child Health Journal. 16(7), 1500-8. doi 10.1007/210995-011-0920-8.

Smith, S A., (2010). Home Visits using a reflective approach improve functional health literacy among low-income pregnant women. Retrieved from http://innovations.ahrq.gov/content.aspx?id=2533.

Smith, S. \& Wollesen, L. (2011). Beginnings Guide: Curriculum implementation manual, $4^{\text {th }}$ Ed. Available from http://www.beginningsguides.com/upload/HVHandbook2011.pdf.

Smooth Way Home https://www.swhd.org/.

Spittle, A., Anderson, P.J., Lee, K.J., Ferretti, C., Eeles, A., Orton, J., et al. (2010). Preventive care at home or very preterm infants improves infant and caregiver outcomes at 2 years. Pediatrics, (126), e171-2178.

Stacey, S., Osborn, M., \& Salkovskis, P. (2015). Life is a rollercoaster...What helps parents cope with the Neonatal Intensive Care Unit (NICU)? Journal of Neonatal Nursing, 21(4), 136-141. doi:10.1016/j.jnn.2015.04.006.

Stark, D. R., Gebhard, B. \& DiLauro, E. (2014). The Maternal, Infant, and Early Childhood Home Visiting Program: Smart Investments build strong systems for young children. Washington, DC: Zero to Three Policy Center.

Subramanian, S., Katz, K.S., Rodan, M., Gantz, M.G., El-Khorazaty, N.M., Johnson, A., et al. (2012). An integrated randomized intervention to reduce behavioral and psychosocial risks: pregnancy and neonatal outcomes. Maternal Child Health Journal, 16(3), 545-554.

Sullivan, P. \& Knutson, J. (2000). Maltreatment and disabilities: A population-based epidemiological study. Child Abuse \& Neglect, 24 (10), 1257-1273.

Sutter-Dallay, A.L., Murray, L., Dequae-Merchadou, L., Glatigny-Dallay, E., Bourgeois, M.L., \& Verdoux, H. (2011). A prospective longitudinal study of the impact of early postnatal vs. chronic maternal depressive symptoms on child development. European Psychiatry, 26(8), 56-70. 
Running head: I/ECMH in NICU

T., et al.eeters, A. R., Ammerman, R. T., Shenk, C. E., Goyal, N. K., Folger, A. T., Putnam, F. W., et al. (2016). Predictors of maternal depression symptom trajectories over the first 18 months in home visiting. American Journal of Orthopsychiatry. Advance online publication. http://dx.doi.org/10.1037/ort0000159.

The Committee on Psychosocial Aspects of Child and Family Health. (2010). Clinical Report Incorporating recognition and management of perinatal and postpartum depression into pediatric practice. Pediatrics, 126(5), 1032-1038.

Tomlin, A.M., \& Viehweg, S.A. (2003). Infant mental health: Making a difference. Professional Psychology: Research and Practice, 34(6), 617-625.

Tomlin, A. M., \& Viehweg, S. A. (2016). Tackling the tough stuff: A home visitor's guide to supporting families at risk. Brookes: Baltimore.

Tough, S. C., Siever, J. E., Leew, S., Johnston, D. W., Benzies, K., \& Clark, D. (2008). Maternal mental health predicts risk of developmental problems at 3 years of age: follow up of a community based trial. BMC Pregnancy and Childbirth, 8(16), 1-11.

VandenBerg, K. A. \& Hanson, M. J. (2013). Coming home from the NICU: A guide for supporting families in early infant care and development. Baltimore: Brookes.

Weatherston, D. J. (2000). The infant mental health specialist. Zero to Three, 21(2), 3-10.

Weatherston, D. (2005). Returning the treasure to babies: An introduction to infant mental health service and training. In K. M. Finello (Ed.), The handbook of training, and practice in infant and preschool mental health (pp. 3-30). San Francisco: Jossey-Bass.

Weatherston, D., Kaplan-Estrin, M., \& Goldberg, S. (2009). Strengthening and recognizing knowledge, skills, and reflective practice: The Michigan Association for Infant Mental Health Competency Guidelines and Endorsement Process. Infant Mental Health Journal, 30(6), 648-663.

Weck, R. L., Paulose, T., \& Flaws, J. A. (2008). Impact of environmental factors and poverty on pregnancy outcomes. Clinical Obstetrics and Gynecology, 5(1), 349-359.

Weitzman, C. \& Wegner, L. (2015). Promoting optimal development: Screening for behavior and emotional problems. Pediatrics, 135(2), 3840395.

Welch, M.G., Firesten, M.R., Austin, J. Hane, A.A., Stark, R.I., Hofer, M.A., .. \& \& Myer, M.M. (2015). Family nurture intervention in the neonatal intensive care unit improves social-relatedness, attention, and neurodevelopment of preterm infants at 18 months in randomized controlled trial. Journal of Child Psychology and Psychiatry., 56(11): 1202-11.

Wesley, P. W. \& Buysee, V. (2001). Communities of practice: Expanding professional roles to promote reflection and shared inquiry. Topics in Early Childhood Special Education, 21(2), 114-123.

Willheim, E. (2013). Dyadic psychotherapy with infants and young children, Child and Adolescent Psychiatric Clinics of North America, 22, 215-239.

Williams, J., Schore, S. E., \& Foy, J. M. (2006). Co-location of mental health professionals in primary care settings: Three North Carolina Models. Clinical Pediatrics, 45(6), 537-543.

Wollesen L, \& Peifer K. (2006). Life skills progression. An outcome and intervention planning instrument for use with families at risk. Baltimore: Paul H. Brookes Publishing Co.

U.S. Department of Health and Human Services. (2013). Transitioning Newborns from NICU to Home: A Resource Toolkit. AHRQ (Agency for Healthcare Research and Quality) Publication No. 12(14- 
Running head: I/ECMH in NICU

0054-EF. Rockville, Maryland. Retrieved from

http://www.ahrq.gov/professionals/systems/hospital/nicu_toolkit/index.html.

US Department of Health and Human Services. Births: Preliminary Data for 2010. National Vital Statistics Reports. (November 2011). CDC National Center for Health Statistics.

Zeanah, P.D., Larrieu, J.A., \& Boris, N.W. (2006). Nurse home visiting: Perspectives from nurses. Infant Mental Health Journal, 27(1), 41-54. 